\title{
EL SISTEMA UNIVERSITARIO Y LA VINCULACIÓN CULTURAL CON EL MEDIO
}

\author{
Luis Merino*
}

* Director ejecutivo del Centro de Extensión Cultural de la Universidad de Chile 


\section{RESUMEN}

En este artículo se analiza la vinculación cultural de las universidades chilenas con el medio social, conocida habitualmente como extensión, y las diversas dificultades a la que se ve enfrentada en la actual coyuntura de mercado y globalización. Desde la particular experiencia del autor en la Universidad de Chile, se examina la vertiente unidireccional -desde la institución hacia el medio-a la que históricamente ha estado expuesta, para finalmente abogar por una vinculación cultural de la universidad que se aborde bidireccionalmente, es decir, recogiendo también las necesidades y aspiraciones de la sociedad, con alianzas hacia el interior del sistema universitario y con otras organizaciones que permitan la diversificación de su financiamiento, y recogiendo también el aporte de la cultura chilena en el exterior. Sólo con esta disposición, entre otras medidas, podrán las universidades superar su enclaustramiento y recuperar su carácter de referentes culturales.

\section{ABSTRACT}

The paper analyzes the cultural relationship between Chilean universities and the social setting of which they are part, generally known as outreach, and the various difficulties they currently faces in view of the circumstances created by the market and globalization. From the author's own perspective and experience at the Universidad de Chile, the article analyzes a unidirectional approach -i.e. from the institution towards the setting- to which it has been exposed in historical terms, and advocates in favor of a cultural link for universities approached from both sides, that is, one that also takes into account the needs and aspirations of society, by forging alliances within the university system and other organizations to allow to diversify the source of funding and also bring in the contribution of Chilean culture from abroad. Only if a willingness of this type exists -among other measures-will universities be capable to overcome their isolation and recover their quality of being cultural points of reference. 


\section{EL SISTEMA UNIVERSITARIO Y LA VINCULACIÓN CULTURAL CON EL MEDIO}

Una mirada de conjunto al sistema universitario revela una realidad profundamente heterogénea, donde coexisten universidades públicas con universidades privadas; universidades simples, esto es, que cultivan prioritariamente la docencia como función universitaria, con universidades complejas, que cultivan además la investigación, la creación artística y la extensión; universidades de más de un siglo de funcionamiento con universidades de creación reciente, como son, además de las universidades privadas, aquellas del Consejo de Rectores que surgieron de la reestructuración de universidades tradicionales tales como la Universidad de Chile, la Pontificia Universidad Católica y la ex Universidad Técnica del Estado (en la actualidad, Universidad de Santiago).

La vinculación cultural de las universidades con el medio se puede definir como una forma de interacción, mediante la cual una institución ofrece al país un servicio docente o de investigación, un bien simbólico o un conjunto de bienes simbólicos, como parte del cumplimiento de su misión.

En términos genéricos, esta actividad se agrupa bajo la función de extensión, la que fue establecida inicialmente por la Universidad de Chile en su Estatuto del año 1931. Generalmente, esta es una función unidireccional, esto es, se dirige desde la universidad al medio social. Se buscó transformar la vinculación cultural en bidireccional durante la reforma de la Universidad de Chile en 1968, dirigiéndola también desde el medio hacia la universidad. No obstante, a raíz de la intervención de que fueron objeto las actuales universidades del Consejo de Rectores durante el período del gobierno militar, la relación se reestableció como unidireccional y así se ha mantenido hasta hoy día. 
La Universidad de Chile es, sin duda, la institución pionera en nuestro país en lo que concierne a la ligazón cultural con el medio. Dentro del marco del Estatuto de 1931 se establecieron organismos tales como la Orquesta Sinfónica de Chile, el Ballet Nacional Chileno, el Coro de la Universidad de Chile, la Revista Musical Chilena, el Teatro Experimental, el Museo de Arte Contemporáneo, el Museo de Arte Popular Americano, el Instituto de Extensión Musical y el Instituto de Extensión de las Artes Plásticas, entre las principales agrupaciones de carácter artístico-cultural. Por otra parte, las Escuelas de Temporada permitieron, durante más de treinta años, establecer relaciones con la sociedad a través de actividades preferentemente docentes. A éstas se deben agregar otros organismos que establecieron una vinculación con el medio a través de actividades de investigación. Dentro de esta última línea, se pueden señalar el Instituto de Investigaciones Musicales de la Facultad de Bellas Artes, pionero en el estudio de la música de tradición oral de Chile, el Instituto de la Isla de Pascua, a cargo de la Facultad de Arquitectura, el Centro de Estudios Judaicos y el Centro de Estudios Árabes, a cargo de la Facultad de Filosofía y Humanidades.

En el caso de la Universidad de Chile, el perfil institucional de su extensión se dio dentro de una universidad pública, la de mayor antigüedad dentro del sistema universitario nacional y con una alta complejidad académica, puesto que esta vinculación cultural estaba íntimamente ligada con las funciones de docencia, investigación y creación artística. Durante el período 1930-1973 esta actividad se sustentó en un financiamiento preeminentemente estatal, casi como una delegación por parte del Estado, el que, durante este período, careció de un aparato cultural propio. De este modo, la Universidad de Chile se transformó en un referente cultural para el país, al ser el organismo que dio a conocer a los chilenos las manifestaciones artísticas de vanguardia junto a las grandes obras de la tradición europea, además de la creación artística chilena y latinoamericana en el campo de la música, la danza, el teatro y las artes plásticas.

Este perfil también se apreció en otras universidades complejas, como la Pontificia Universidad Católica y la Universidad de Concepción. Se pueden mencionar, entre otros, al Teatro de Ensayo de la Universidad Católica, además de la Orquesta Sinfónica, el Coro y la Pinacoteca de la Universidad de Concepción, organismos, estos 
últimos, que han tenido una gran importancia en la actividad cultural del sur de Chile.

Con el advenimiento del gobierno militar, se inició un período, entre los años 1973 y 1980, que se podría denominar "de transición". En general, el área artístico-cultural se vio fuertemente afectada, debido a la exoneración de una parte considerable del personal académico por causas ideológicas y políticas. Por otra parte, se mantuvo el statu quo en términos de financiamiento estatal a las universidades, y continuó la actividad de los organismos de vinculación cultural universitaria con personal que no fuera objetado por las autoridades delegadas en las distintas universidades estatales.

El período comprendido entre los años 1980-1990 se caracterizó por una escisión entre el Estado y las universidades pertenecientes actualmente al Consejo de Rectores. A la disminución generalizada del aporte estatal directo, que afectó con mayor fuerza a la Universidad de Chile, se agregó el surgimiento de un sector cultural alternativo privado, el que estuvo conformado en gran parte por personas exoneradas de las universidades estatales o por personas jóvenes quienes, si bien mantenían algunos nexos con las universidades estatales, preferían ejercer su actividad artístico-cultural fuera de ellas, debido al mayor grado de libertad creativa de que podían disfrutar.

Con el advenimiento de la democracia el año 1990, y durante los últimos 14 años, se mantuvo, con cambios menores, el sistema de financiamiento estatal a las universidades del Consejo de Rectores generado durante el gobierno militar. Si bien se recuperó la libertad creativa, la actividad de vinculación cultural universitaria con el medio se enfrentó al desafío de conjugar financiamiento y misión, ante la necesidad de buscar recursos fuera del sector público, debido a la disminución del financiamiento estatal directo.

A pesar del éxito de más de una década en la aplicación de la llamada "Ley Valdés", las recientes medidas del gobierno han generado dificultades e incertidumbres en lo que respecta a incentivar al sector privado a entregar aportes a la actividad de vinculación cultural de las universidades. Por otra parte, se inicia una participación creciente del Estado en la actividad cultural, que se inserta por aposición al sistema de extensión cultural universitario. 
Esta mayor incidencia se advierte en el desarrollo del Fondo Nacional de Desarrollo Cultural y de las Artes (Fondart), la creación del Consejo Nacional de la Cultura y las Artes, un servicio con el rango de Ministerio de Cultura, del que surgirá una red de consejos nacionales y regionales que tendrán a su cargo la asignación de fondos públicos para la creación en diversas disciplinas artísticas.

Por todas partes afloran en la actualidad características de un sistema no consolidado, y no de uno que permita una vinculación cultural fluida de las universidades con el país. Las grandes inequidades sociales de Chile se conjugan con el acceso desigual de las personas a los bienes simbólicos. En tal sentido, la vinculación cultural de las universidades al medio requiere alfabetizar a un gran grupo de la población en las bases de la cultura y el arte, más que en las manifestaciones de la vanguardia internacional o de Chile y América Latina, las que resultan familiares a un público más bien minoritario, educado gracias a esta vinculación cultural en las décadas de 1940, 1950 y 1960.

Otro factor tiene que ver con la naturaleza de los tiempos que vivimos. Nos encontramos en la era de la desmecanización de la materia y de la circularidad en la cibernética, sustitutiva de las clásicas relaciones lineales de causalidad. A pesar de la revolución profunda que ha significado la globalización de las comunicaciones, se advierte un elevado nivel de incertidumbre en la búsqueda de sentidos universales. Parafraseando las palabras de un destacado pensador y humanista chileno, Félix Schwartzmann, la única certeza posible hoy día en este aspecto es la carencia de ella.

Esto se hace patente en la así llamada "modernidad latinoamericana", o el proceso de inserción de los países latinoamericanos en los patrones de la sociedad compleja y funcionalmente diferenciada característica de la Edad Moderna (analizados con detenimiento por Max Weber y por tantos otros estudiosos posteriores). Según el cientista social chileno José Joaquín Brünner, "las culturas de América Latina, en su desarrollo contemporáneo, no expresan un orden -ni de nación, ni de clase, ni religioso, ni estatal, ni de carisma, ni tradicional, ni de ningún otro tipo-, sino que reflejan en su organización los procesos contradictorios y heterogéneos de 
conformación de una modernidad tardía, construida en condiciones de acelerada internacionalización de los mercados simbólicos en el ámbito mundial".

Nos encontramos, además, dentro de procesos de complejas y laboriosas transiciones, en lo político y lo económico, hacia la consolidación de sistemas caracterizados por la autonomización y autorregulación creciente de las esferas importantes de la sociedad.

Para entender esta falta de consolidación, debemos tener en cuenta, además, que vivimos los momentos críticos de una etapa de la historia de Occidente, que podría ser caracterizada -de acuerdo al célebre dictum de Hegel-como la de la "liberación de la subjetividad". Hoy día, más que nunca, las universidades, en sus proyectos de vinculación cultural, no deben soslayar la mirada que cada ciudadano tiene de la cultura. Ha llegado el momento de volver a pensar en una relación de las universidades que no sea unidireccional, desde ellas a la sociedad, sino que funcione también en la vía opuesta, esto es, que recoja las necesidades de la ciudadanía para un mejor desempeño de sus funciones docentes, de investigación, creación artística y extensión. Si bien este requerimiento debería ser abordado por todas las universidades del país, considero que es particularmente relevante en el caso de las universidades regionales.

En toda esta actual vorágine, parecería que la actividad de vinculación cultural fuera menos importante que la solución de otros grandes problemas del país. Por el contrario, considero que esta actividad es nuestra mejor carta de presentación en la sociedad mediática globalizada del mundo de hoy. Por otra parte, existe la necesidad de satisfacer las "hambrunas del espíritu" de aquellos hombres y mujeres "que creen que ser es algo más que ser consumidor", de acuerdo a las palabras del economista chileno Manfred A. MaxNeef.

Para abordar este desafío, es necesario pensar en grandes alianzas que consideren la vinculación cultural hacia el medio no sólo como un problema de las universidades, sino como un tema de país, que requiere la acción conjunta del Estado, las universidades, el sector público y el sector privado, además de toda la ciudadanía. Para ello 
resulta fundamental considerar que el financiamiento de proyectos de vinculación cultural con el medio no puede estar sujeto a los mecanismos del mercado. Para el Estado, un financiamiento de esta índole debe tener un fin de inversión social, mientras que para el sector privado el apoyo a proyectos de esta índole debe contar con los incentivos tributarios adecuados.

Dentro de esta necesidad de grandes alianzas, el gobierno de Chile ha dado una señal poderosa al crear la Comisión Asesora Presidencial para el Bicentenario de la República de Chile. Por su parte la Corporación Patrimonio Cultural de Chile representa una señal igualmente poderosa desde el sector privado. Ambos organismos tienen una función insustituible como articuladores y catalizadores de las múltiples iniciativas que, en torno a la vinculación cultural con el medio, deberán generarse en el futuro próximo, y en las que deberán figurar por fuerza las universidades del sistema nacional.

En este proceso es indispensable considerar también a los alrededor de 630 mil chilenos que viven fuera del país, según cifras oficiales del Registro de Chilenos en el Exterior realizado por la Dirección Consular de la Cancillería y el Instituto Nacional de Estadísticas. Enfatizo este punto, pues la cultura chilena es ya parte del mundo. A modo de ejemplo, se puede señalar que la obra de dos grandes artistas chilenos, como Violeta Parra y Víctor Jara, ha sido ampliamente difundida y estudiada en diversas regiones del mundo, a raíz de la diáspora chilena con posterioridad a septiembre de 1973. Por lo tanto, la vinculación cultural de las universidades no debe confinarse a los límites geográficos del país, sino que desterritorializarse, siguiendo a Néstor García Canclini, a lo largo y ancho del mundo, especialmente a aquellos países con comunidades de compatriotas residentes.

Las grandes alianzas de las universidades entre sí y con los otros sectores señalados les permitirá recuperar ante la sociedad el carácter de referentes culturales que tuvieron en el pasado, superando el enclaustramiento a que las ha sometido un sistema económico atomizador que conspira contra una proyección pública abarcadora, muy necesaria y saludable para el mejor desempeño de sus funciones docentes de investigación, creación artística y extensión. 